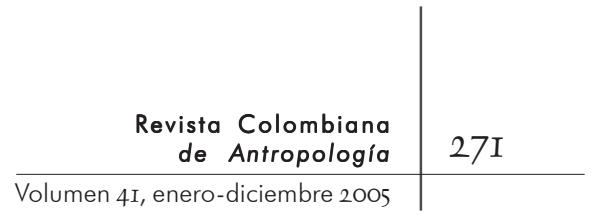

\title{
CANNIBAL TALK: THE MAN-EATING MYTH AND HUMAN SACRIFICE IN THE SOUTH SEAS.
}

Gananath Obeyesekere

University of California Press. Berkeley y Los Angeles. 2005

El CANibalismo ES UNA DE LAS GRANDES OBSESIONES DE OCCIDENTE. Aparte de las múltiples referencias que es posible encontrar de éste en relación con el Otro, al primitivo, hoy puede verse en novelas, cuentos, películas y hasta en las noticias relacionadas con crímenes atroces vinculados a desórdenes mentales y fantasías asesinas, que también pueden asociarse al vampirismo. Algunos arqueólogos y antropólogos físicos se esmeran en encontrar sus huellas en sociedades desaparecidas, huesos humanos con señales de mordidas o en análisis moleculares; antropólogos materialistas deducen que su práctica se debe a la falta de acceso a proteínas, mientras que otros niegan su existencia, pues no hay pruebas fehacientes y registradas con rigor científico al respecto. Otros antropólogos sugieren que el canibalismo hace parte de la manera como se construyen ontológicamente los seres dentro de determinadas cosmologías. En fin, si algo parece cierto en relación con el canibalismo es que está relacionado con la construcción de la alteridad.

El libro Cannibal talk: The man-eating myth and human sacrifice in the South Seas, del antropólogo cingalés Gananath Obeyesekere, tiene el objetivo de explicar algunos aspectos fundamentales sobre el canibalismo. Si bien es cierto que el libro podría tomarse como la continuación de su debate con Marshall Sahlins, debate surgido a partir de los argumentos de Obeyesekere en su libro The apotheosis of captain Cook: European mythmaking in the Pacific (1992) en relación con el libro de Sahlins Islands of history (1987) y cuya respuesta fue How "Natives" think: About captain Cook, for example (1996), Obeyesekere no pretende refutar directamente a Sahlins, sino explicar las razones por las que los europeos siempre estuvieron obsesionados por el canibalismo de los nativos.

A partir de la deconstrucción y restauración de las continuidades y quiebras entre la cultura tradicional o precolonial, en especial de los maorí, y la llegada de los blancos, analizadas en 


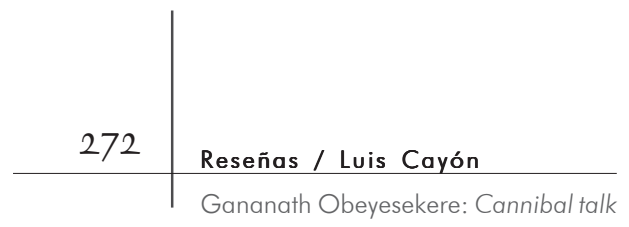

diarios y relatos de viaje que describían al canibalismo como una realidad en los mares del sur, Obeyesekere intenta probar que el canibalismo puede verse como una proyección europea del Otro, y como tal, se deriva del discurso occidental sobre el Otro. Obeyesekere establece una distinción entre el canibalismo y la antropofagia: el primero es discursivo mientras que la segunda es una práctica asociada al sacrificio humano. Al situar al canibalismo como una práctica discursiva, el registro etnográfico está lleno de fantasías como el endo-canibalismo, que no sería más que un tipo de antropofagia mortuoria. Esto sugiere que el canibalismo estaría enmarcado dentro del salvajismo, una suerte de orientalismo, que construyó desde la mirada europea, tanto positiva como negativamente, al salvaje a lo largo y ancho del planeta. Y ello sólo fue posible a partir de las navegaciones y exploraciones de los nuevos mundos descubiertos por los europeos desde el siglo quince, así como a los propios temores europeos y todo su inventario medieval de seres monstruosos y fantásticos.

La preocupación occidental por el canibalismo estaría asociada con las tradiciones mitológicas europeas, que desde los griegos hacen referencia a comer carne humana o a beber sangre humana, y cuyas temáticas recurrentes y reconocidas por los viajeros europeos entre distintas sociedades nativas habrían formado unos mitemas circulantes aplicados indistintamente a los nativos de cualquier parte del globo terrestre. Esto no significa que los europeos estuvieran alejados de la posibilidad de comer carne humana, ya que esta práctica fue validada en los casos en que marineros y náufragos, bajo condiciones de extrema supervivencia, tenían que echar mano de alguno de sus compañeros de infortunio para proveerse de alimento. La legitimidad de esta práctica se oponía a esa visión del nativo como "comedor de hombres" y celebrador de banquetes caníbales, lo que se asociaba también a festines satánicos. Claro, en esa época nadie iba a considerar que buena parte de la persecución que sufrieron los cristianos en Roma hasta el siglo cuarto obedecía a la acusación de que ellos se reunían para comer carne de niños.

Obeyesekere sugiere que la antropofagia en gran escala fue resultado del contacto, ya que los nativos crearon contradiscursos sobre el canibalismo porque pensaron que los europeos eran los caníbales. Pero, ¿por qué los indígenas pensaron que los europeos eran caníbales y se acercaban en ocasiones a ellos para ofrecer alguna porción de carne humana? Hay varias razones, entre 


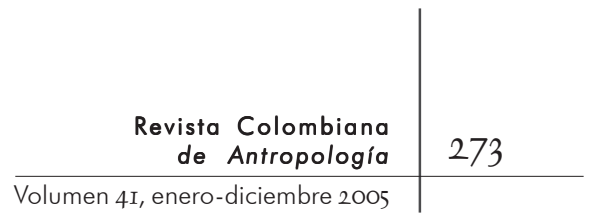

ellas las prácticas de colgar cabezas de nativos en los postes de los barcos para atemorizarlos, o quizá responder simbólicamente a la violencia introducida por el contacto, devorando a los blancos enemigos. De cualquier forma, el sistema sacrificial aborigen se desacralizó y el consumo de carne humana se intensificó.

Sin embargo, hay otras razones que no parecen tan evidentes. En el siglo diecinueve en Europa era común el comercio de cabezas aborígenes con fines de investigaciones en frenología, para alimentar exposiciones y estantes de museos o, simplemente, por motivos estéticos, para adquirir objetos exóticos curiosos. Es evidente que esa demanda por cráneos debió haber incrementado el sacrificio humano en los mares del sur así como las guerras entre grupos, llevando a un proceso de "self-primitivization", que ocurre cuando durante los periodos de relaciones de poder desiguales los nativos adoptan la imagen proyectada sobre sí mismos por el otro colonial.

Las "guerras de mosquetes" designaron las guerras intertribales entre los maorí por la introducción de las armas de fuego, que poseían un gran valor práctico y simbólico entre ellos. El acceso a dichas armas se tradujo en la consecución de esclavos para pagarlas, e implicó la introducción de nuevas formas de guerra y enfermedades. Esto quiere decir que las armas articularon a los maorí dentro del orden capitalista mundial y promovieron alianzas, nuevas formas de expansión predatoria y el surgimiento de caciques empresarios. La intensificación de la guerra ligada con el comercio estaba asociada también con prácticas de guerra nativas tradicionales, como cortar la cabeza del jefe muerto en batalla y el consumo ritual de su cuerpo; así, las muertes aumentaron, se tomaron más cabezas como trofeo -ya no sólo de los caciques- y la antropofagia se volvió indiscriminada, al punto de que se formó un "canibalismo del campo de batalla" que contrastaba con la institución del sacrificio maorí. Esto secularizó la antropofagia sacrificial, sobre todo porque produjo el consumo de blancos. Al comer europeos hubo un quiebre en el antiguo orden simbólico del sacrificio, en el que las víctimas sacrificiales eran comidas como un acto sacramental. Ese canibalismo del campo de batalla, dice Obeyesekere, se convirtió en una nueva tradición construida sobre los viejos cimientos del sacrificio maorí y en el nuevo consumo de blancos; allí, ocurrió una expansión y peyorarización de la comunidad consubstancial -entendida como una comunidad comensal que 


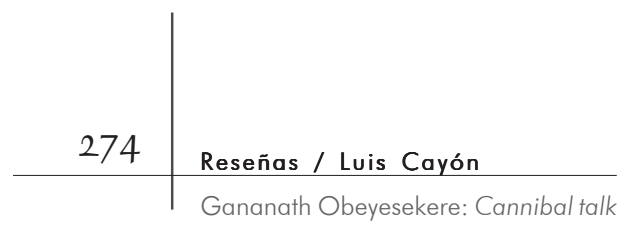

al comer una sustancia consagrada comparte la misma sustancia o naturaleza esencial- que llevó a la pérdida de las regulaciones que ordenaban el sistema sacrificial compartido con otras sociedades polinesias. Los maorí usaron su imagen como caníbales como un escudo protector o como una agresiva "self-primitivization" de cara a las relaciones desiguales de poder y al surgimiento de la colonización en sus territorios. Por eso, el canibalismo del campo de batalla sólo puede ser visto en su propio contexto histórico y socioeconómico, y como resultado de las nuevas relaciones comerciales con Occidente.

La búsqueda de armas de fuego por parte de los nativos formaba parte de un circuito comercial con los británicos, alimentado por esclavos y cabezas trofeo. De esa manera, los europeos se hicieron copartícipes del canibalismo motivado por el capitalismo emergente. Obeyesekere afirma que la esclavitud está relacionada con la metafísica del salvajismo, donde los teólogos jesuitas asumieron el concepto aristotélico de la "esclavitud natural”, es decir, la idea de que algunos grupos de personas debían servir como esclavos para otras; por esto, al confrontarse con los grupos nativos era evidente su carácter servil. Ello permitió equiparar la concepción de salvajismo con un estado natural que inferioriza al Otro, lo que, además, se relacionó con la idea de una polución satánica perceptible en las prácticas de canibalismo, sodomía, bestialismo y otras cuestiones consideradas como paganas. De ahí que el canibalismo existiera para los europeos en todos los rincones del planeta desde el siglo quince. El canibalismo como manifestación fundamental del salvajismo, se oponía dialécticamente a la civilización, en la cual Dios había dado como don las nociones de racionalidad asociada al pensamiento científico, el progreso y la sociedad civil. Esto también oponía el paganismo al cristianismo, y servía para definir las diferentes identidades. Por esto, en los relatos analizados es perceptible un proceso de construcción imaginada de sí mismos de los narradores occidentales, basados en sus valoraciones y modelos sobre los nativos.

La creencia que los nativos comían carne humana era un preconcepto que servía para identificar genéricamente al indígena como caníbal e imaginarlo como tal en cualquier parte del mundo. La idea para los europeos era que el Otro podía comerlos. Pero ello no estaba tan alejado de las creencias católicas sobre la eucaristía, que según Obeyesekere es una forma de canibalis- 


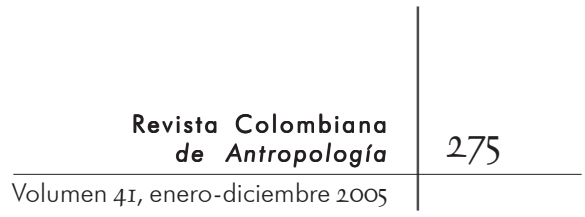

mo, ni de las prácticas de los colonizadores que exhibían las cabezas de los nativos en los postes de los barcos. Tampoco estaba alejado de otras prácticas familiares en Europa, donde era común el descuartizamiento de criminales y traidores; dichas prácticas fueron aplicadas también por españoles y portugueses en sus colonias para tratar a quienes se rebelaban contra la Corona. Dar una muerte humillante a dichos individuos tenía implicaciones teológicas, ya que el desmembramiento de los cuerpos impedía la resurrección, pues quebraba la unidad total del cuerpo para el fin de los tiempos, se impedía la sepultura cristiana y el alma de los traidores era animalizada. Ver replicados estos descuartizamientos en el canibalismo indígena apuntó al hecho de que en la imaginación europea estuvieran fundidos el canibalismo y el descuartizamiento, par de hechos asociados en todas las representaciones gráficas hechas por europeos sobre el canibalismo de los nativos.

A comienzos del siglo diecinueve, los actos de violencia en masa en Europa execraban los cuerpos: había castramientos, mutilaciones, se arrancaban ojos y lenguas, y había decapitaciones. Solamente pensemos en las ejecuciones de la revolución francesa un par de años antes, para corroborar dichas apreciaciones, o en los argumentos de Nietzsche en la Genealogía de la moral, obra que muestra toda negación de la reciprocidad simétrica y cuestiona las bases universales del don de Mauss. No obstante, esas experiencias que vivió Europa, es decir, su propio salvajismo, fueron proyectadas al Otro formando un conjunto de historias y relatos caníbales. El espectáculo de la violencia de masas europea, la cual equaciona la víctima con el animal, descuartiza el cuerpo, empala a la víctima, toma chivos expiatorios, danza alrededor de una pira ardiente, degrada los cuerpos, desmembra y toma partes del cuerpo como trofeo, evoca las descripciones de los banquetes caníbales imputados a los nativos. Por eso, Obeyesekere considera que en los ofrecimientos de carne humana hechos por los nativos a los europeos podría encontrarse el ofrecimiento ceremonial de una porción de carne de un grupo de caníbales a otro.

Todos los aspectos presentes en estas prácticas y representaciones occidentales, así como en sus creencias cristianas, traen a colación mitemas familiares. Con mitemas Obeyesekere quiere decir temas míticos o fragmentos y piezas de representaciones culturales, que forman parte de la memoria cultural y están incor- 


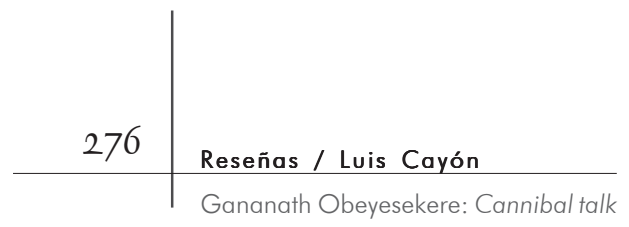

porados en la conciencia pública por medio de historias, folklore y representaciones periodísticas. Desde mi perspectiva, el argumento de Obeyesekere es convincente hasta este punto del libro, pues en el desarrollo de su argumentación muestra cómo Occidente proyectó y construyó a los nativos como caníbales, algo que aún no sale del sentido común occidental, y hace evidente que, en realidad, el blanco es el gran caníbal. Encuentro ecos de esta argumentación en las situaciones vividas por los indios en los campamentos caucheros de la casa Arana a inicios del siglo veinte, donde los indios que actuaban como capataces de los indígenas cautivos fueron obligados a practicar rituales de antropofagia para complacer a sus patrones y corroborar que de verdad los indios eran caníbales. De manera semejante, las acusaciones de canibalismo actuaron durante la conquista portuguesa y española de América para promover las guerras justas, cuyo desenlace era la esclavitud y la reducción a la vida civilizada.

Sin embargo, de aquí en adelante Obeyesekere entra en el mundo de las explicaciones psicológicas y tira por la borda toda su argumentación. ¿No bastaba con examinar la manera de construir la alteridad? ¿Por qué debía entrar a explicar las causas iniciales de los fenómenos? ¿Más aún si el autor no nació en Occidente, y al tiempo que por ello puede tener otra mirada cuya crítica es evidente en todo el libro, termina comprando los postulados de la psicología freudiana? A la hora de la verdad, ese giro en la explicación me parece más enigmático que el propio canibalismo. Según Obeyesekere, la reproducción de estos mitemas en formas de violencia colectiva son interpretados como mitemas flotantes en un campo de ansiedades. Desde la mirada freudiana, las ansiedades son producidas por el peligro o el miedo, ya sea a agentes externos o internos. De esta forma, los mitemas flotantes y las ansiedades libre-flotantes están intrínsecamente conectadas y surgen en el campo de la conciencia durante contextos específicos, en especial de violencia de masas.

Dichos mitemas son transferidos a la acción para reproducir en los otros reacciones miméticas o imitativas. Dichos fragmentos de memoria flotante dentro del campo de la conciencia pueden coexistir con profundas motivaciones de cuño freudiano, como el temor a la castración, o sea a la mutilación del propio cuerpo, que explicaría la práctica de la decapitación, cuyas bases estarían en la violencia masculina y las ansiedades por el miedo a la castración. Así que al transferir a los nativos dichos 


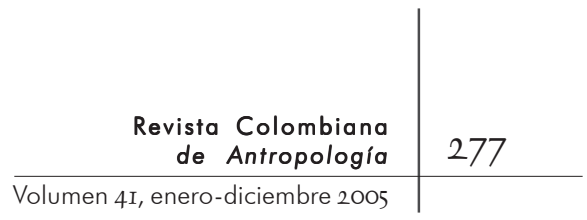

temas recurrentes, en un contexto de ansiedad producido por los nuevos contactos, se creó una imaginación paranoica que convirtió prácticas nativas, como el sacrificio, en canibalismo. Ese estado paranoide no permitía distinguir los peligros imaginarios de los reales, transformando a unos y otros en una realidad psíquica. La imaginación paranoica apareció y reapareció todo el tiempo en esos mundos aislados en los que los europeos ponían pie por primera vez. Por ello, las representaciones coloniales sobre la antropofagia ritual absorbieron el mito europeo del comedor de hombres. De esta manera, Obeyesekere reduce sus argumentos al temor occidental al Otro.

Esto es interesante a las luces de la etnografía amazónica, donde más que temor existe una exaltación al Otro, quien es indispensable para la reproducción social. Curiosamente, dicha relación está formulada en términos de canibalismo, el cual va más allá de prácticas asociadas al sacrificio humano y constituye toda una teoría indígena sobre el cosmos, la alteridad y la ontología. En realidad, ese Otro que se consume o se incorpora de distintas maneras en las cosmologías amazónicas trasciende el materialismo de la mirada de Obeyesekere, quien queda preso en la necesidad de explicar si existió o no el canibalismo. Sin embargo, el libro tiene un gran mérito, pues nos hace preguntar si es al Otro a quien en realidad debemos temer, o imás vale temer a nuestras propias ideas y preconceptos?

LUIS CAYÓN

Estudiante de doctorado, Universidad de Brasilia

luiscayon@hotmail.com 